\title{
On the Form of "Sex" Cultural Elements in the Clothing Advertising Communication
}

\author{
Duanwu Shang \\ City College, Wuhan University of Science and Technology, Wuhan, Hubei, China
}

Keywords: "Sex" cultural elements; The clothing advertising; Communication; The form

\begin{abstract}
In the modern civilized society, "sex" has the endless charm to the person, using "sex" as a sale communication tool has become a familiar phenomenon. Particularly prevalent in the clothing advertising communication, using "sex" as an appeal is a customary manoeuvre innumerous clothing brand. The form of "sex" elements in the clothing advertising communication can conclude, the functional type "sex appeal", the symbol "sex appeal", the chip type "sex appeal", the conceptualization "sex appeal". The use of "sex" cultural elements should adhere to the principle of "moderate", and combine with the particular culture, strive to achieve the unity of clothing advertising communication's aesthetic value and economic value.
\end{abstract}

\section{Introduction}

"Sex" as a social cultural phenomenon, which lays a deep imprint in different historical stages in the evolution of the clothing. From clothing "sex" Origin theory to "sex" as the formation of human sexual symbols of clothing patterns, and people wear psychology and sexual attraction of open concept prompted by sexy clothing, you can see "sex" mark on the costume culture development. "Sex" is the natural law of human existence, is one of the most basic desire, the clothing advertising as the main communication carrier of promotional clothing and their brand, demands of expression for "sex" seems to be an international trend. According to the survey shows that women's response to fitness male model almost with men's response to female model, which is no significant difference. Therefore, using "sex" as an appealing way is a customary manoeuvre innumerous clothing brand.

Throughout the domestic and foreign clothing advertising, it is easy to find that the form of "sex" elements in the clothing advertising communication, can be roughly summed up in the following categories:

\section{The Functional Type "Sex Appeal"}

So-called functional type "sex appeal", is one of the common advertising communication form, which use "sex" as the creative points, namely "sex" appeal point in the clothing advertising directly associated with the product, the use of "sex" element is in order to improve the attention of products, and contribute to purchase behavior. In the clothing plane advertising, designers often through direct display method to symbolic the external, visible product quality or function, and select the appropriate and unique point of sex appeal.

For example, Bamboo bra advertising, the picture is two breast shape of watermelon and brand name, while Vassarette underwear ads, even this technique need not to use, just build the the rich sexy atmosphere - in downy lamplight, showing women's underwear hanging on the back of the chair. Another example, in 2006 won the Cannes Lions advertising festival, Levi 's fine tight jeans, give a person particularly impressive. Five graphic works style is consistent, picture is very simple, mainly with a single line draw the outline of the shape of men and women, black and white on the equivalent of leg ministry line has a small piece of Levi 's orange trademark in rectangle. By the delicacy of line contact later to put on jeans slim body, pure and simple, make full use of the young people want to slim, hold fast to the word "fine" sex appeal, and push it to the extreme, leave no room for manoeuvre. In addition to the unique appeal point, creative originality and impact has perfectly reflected in this series of Levi 's plane advertising works. 


\section{The Symbol Type "Sex Appeal"}

So-called symbol, it is an artistic technique which shows similar or similar concepts, ideas, or feelings by a specific image association. Symbol is not a representation, it is a representative. It is established as a result, it becomes objects, and gets the meaning, is generated by long time many personal feeling association, it becomes no necessary or intrinsic link between objects. The symbol type "sex appeal" clothing advertising, use a specific symbol as a sex symbol, such as through models vigorous, beauty, health, beautiful body lines and strong muscle's symbolic significance, shows consumers with their charm, sexy revealed his bones.

Modern consumer spending has not just as a physical commodity, also includes the commodity symbolic significance. Advertising for items symbolic given just as human part of the process of symbolization, reflected in the material need to be basically met, a higher level of human needs. In a certain sense, the symbolism is a symbol of the highest level of "manipulation", it can strong brand and add product value, at the same time can form a strong brand image in consumers' mind, easy to form brand myth. Known as " The Marlboro Man ", has opened up a new epoch of symbol. The "cowboy" image has long been the global advertising people as "brand image" cult classic, from the United States Cowboy's pursue free, wild and adventurous external appearance to inner character of strength and independence. Similarly, in the clothing advertising communication, the symbolic meaning of symbolic also let people indulge, thrall. Levi 's advertising make people feel that it not only wear a pair of jeans so simple, but also the experience of Levi 's culture and American western frontier force and spirit. Deisel advertising, let a person feel Deisel clothing is a symbol of sexy halfback, etc. Nike AD to make people feel a kind of supreme spirit of sports, and so on. Advertising for items symbolic given just as human part of the process of symbolization, shows people the pursuit of the highest level. Ads combine a pure material products with some kind of unrelated "humanity", given by the product itself does not have the "symbolic", and the virtual symbol transplantation into the mind of the consumer, so as to produce the huge spread utility and commercial utility.

\section{The Chip type "Sex Appeal"}

So-called chip type "sex appeal" namely clothing advertising content does not involve clothing products themselves, the sexual information occupys a large amount of space, in order to attract attention, convey the brand concept or highlight its brand personality. With the vision economy of the development, this kind of clothing advertising seems to be getting into people's horizons, many brands are playing "pin".

For instance, Whisper's pads, have launched an online advertising: played an animated mandressed in black, a line of words appeared above "click on me, you can find what you are yearning for a long time!" Pointed later, the man took off his coat, commentary was: "don't be shy, let's continue." Continued to click, animated man vested off again, commentary was: "feed, you come true?" "You haven't seen the best part." Clicked again, the man took off his trousers, weared only a pair of shorts, commentary: "believe me, you haven't seen the best part!" Clicked again, I saw the man in that animated shorts pulled down rapidly at the same time with a black cover instead of the shorts, commentary was: "good good, I give up, come on..." Clicked again, the fig slowly zoomed in, occupyed most of the picture, and on the right side hit the slogan: "new Whisper black pads, are exclusively for women."

Perhaps this method is called "risk creativity ",which is an advertising communication strategy of the enterprise . while how to do, to sell products, does not damage the brand image, to effectively control the risk degree, this is what advertisers should be considered before making risk creativity.

\section{The Conceptualization "Sex Appeal"}

Along with the development of The Times, the concept of "sex" present the diversification trend , "sex" not only singlely refers to the exposure of the body, such as the chest and waist, hips, legs and 
other parts, such as the collar and shoulder also cannot resist the attraction, the focus of the clothing advertising design begins to turn from the chest to the shoulders and arms, etc. Or heterosexual intimacy, also including homosexual warm hide, etc. Sexy has a new interpretation, for instance, health is considered to be sexy, personality of life status, also known as sexy, and so on. "Sex appeal" clothing advertising communication techniques also break the routine, then present the diversification.

In a group of Dior's $\mathrm{AD}$, the designer's creative style and shooting techniques were very clever. In the two images, only used a hazy warm light, intercepted the female body parts (hand) on the female genitals and neck close-up, no exposed parts, however, the model's hand could talk, and fully demonstrated the dynamic beauty and meteored up a person infinite desire and imagination space, this advertising made people not forget their pictures, and believed that sexy had another interpretation.

In another plane advertising of Dior, Dior's sexy, luxurious by gay model between warm hide, showed a kind of "taboo" or "blindness" of aesthetic feeling. Levi's used men and women models to wear Levi's jeans, four legs consolidated into two legs by partial occlusions, sexy and warm hide, full of interest, which made the audience visual stimuli novelly. Same with benetton ads: the priest and nun to kiss, and the priest and nun was black and white. The "do nothing" creativity and visual impact were overturned thoroughly religious taboos, in order to appeal their own brand "color", against the tide, pastored with the black priest and the white nun "deviant" behaviour, to appeal benetton from diameter value of the brand personality, so as to convey the benetton still the world's true colors attitude and desire, let all love to break through the traditional taboos and bound.

\section{Summary}

Due to customs and national culture are different from country to country, the public accept sexual appeal advertising differently. For example, in the United States, sexual mores open relatively ,naked body has been commonplace in the clothing advertising, but in Arab countries, the sexual idea is quite conservative, for instance, an $\mathrm{AD}$ just because a little girl wanted more and licked lips lens, which is considered a floating particle and was banned.

In China's case, It is not a long abstinence in the country, and the spread of the folk culture also become prosperous, therefore, relative to the countries of the Arab culture, the Chinese for "sex" have more inclusive and loose degree. However, since the han dynasty, the Chinese regard sex as personal privacy, not publicly discussed, and the bondage of feudal ethical from song dynasty to qing dynasty, the Chinese think "led by the evil Yin," sex is unclean. Therefore, compared with the European and American countries, the Chinese attitude towards sex is much more implicative and convergence. In addition, the repression of human nature, to a certain extent, increase the mystery of sex, makes people more longing and desire for sex. In this vision and taboo of ambivalence, the use of "sex" element in the clothing advertising communication is a double-edged sword, must be careful to use, it can play an unexpected effect in the clothing sales, but if use not well, it can let a person feel advertising style low, even nasty, witch can damage the goods itself, and harm to society.

As a qualified designer, you should be able to draw on advantages and avoid disadvantages, to further mine "sex" cultural element in many forms in the clothing advertising communication. In sexy advertising creative practice, should adhere to the moderate principle, the technique of expression Should not too straightforward, implicative inside collect, both to attract audience "eyeball", and to control within the scope of the audience's psychological acceptance, don't repels the audience. In particular, might focus on the following:

First of all, the use of "sex" element is a common and special, the dynamic clothing advertising creative expression skills. To clear the form of sexy advertising, stop sexy advertising which is unrelated goods, and pay attention to the goods personality, avoid shallow vulgar sexy advertising.

Second, must be good at discovering colorful form "sex" elements, combine with the particular culture and customs, cleverly performance clothing brand personality. The life interest and cultural implication, is the sign of successful sexy advertising. 
Moreover, good clothing brands should be according to their own personality, determine whether or not remade "sex" element as the breakthrough point of the brand image. If so, should creatively combine with "sex" element and traditional or modern culture essence, brand personality, form the unique brand personality.

In a word, sexy advertising is elegant or vulgar, poverty or good. The use of "sex" elements, only the integration of culture, can reveal the infinite charm, finally realize the organic integration of the aesthetic value and economic value.

\section{Acknowledgments}

This paper was supported by " Hubei province scientific and technological research project (Project number is: B2017421)".

\section{References}

[1] Xiyuan Qin, Duanwu Shang: Writer, Vol. 541 (2014) No.6, p.215-216.

[2] Yao Li, Wang Li: Advertising Creative and Case Analysis (Higher Eeducation Press, China2014)

[3] Peng L. Individual Vision and Peak Distribution in Collective Actions [J]. Communications in Nonlinear Science and Numerical Simulation. 2017, 47: 238-252.

[4] Licheng Ye: Dress Aesthetics (China Textile University Press,China2013)

[5] Bin Xu, Jing Wu: Clothing AD (China Textile University Press,China2016)

[6] Ping Zhao: Clothing Marketing (China's Textile Press, China2015)

[7] Ju Ning n:The Clothing Marketing Practices and the Case Analysis (The Textile Industry Press, China2012)

[8] Tao Liu: The Mystery of the Clothing Ads (Guangdong Economic Press, China2014)

[9] Information on http://www. ef360. com

[10] Information on http://www. addown. com

[11] Information on http://www. g1r163. com

[12] Information on http://www.cnad.com 